\title{
Effect of Coriolus versicolor glucan on the stimulation of cytokine production in sarcoma-180-bearing mice
}

\author{
ANNOOR AWADASSEID ${ }^{1}$, KUUGBEE EUGENE $^{1}$, MAYADA JAMAL $^{2}$, JIE HOU $^{1}$, \\ AHMED MUSA HAGO $^{3}$, YASER GAMALLAT ${ }^{1}$, ABDO MEYIAH $^{1}$, DJIBRIL BAMBA $^{1}$, \\ CHIWALA GIFT $^{1}$, MOHNAD ABDALLA ${ }^{4}$, YUFANG MA ${ }^{5}$ and YI XIN ${ }^{1}$ \\ ${ }^{1}$ Department of Biotechnology, Dalian Medical University, Dalian, Liaoning 116044, P.R. China; ${ }^{2}$ Department of Geology, \\ University of Kordofan, El-Obeid 51111, Republic of Sudan; ${ }^{3}$ Department of Pathology and Pathophysiology, \\ Dalian Medical University, Dalian, Liaoning 116044; ${ }^{4}$ Department of Biochemistry and Molecular Biology, \\ School of Life Science, University of Science and Technology of China, Hefei Shi, Anhui 230000; \\ ${ }^{5}$ Department of Biochemistry and Molecular Biology, Dalian Medical University, \\ Dalian, Liaoning 116044, P.R. China
}

Received May 24, 2017; Accepted September 19, 2017

DOI: $10.3892 /$ br.2017.999

\begin{abstract}
Coriolus versicolor (CV) contains high levels of bioactive compounds, including the glucan $(1 \rightarrow 6)-\alpha$-D-glucopyranosyl. However, there is a lack of data regarding the potential effect of this $\mathrm{CV}$ glucan $(\mathrm{CVG})$ on the stimulation of cytokine production. The present study evaluated the effect of CVG on the stimulation of cytokine production in sarcoma-180-bearing mice. Mice were treated with three doses of CVG (40, 100 or $200 \mathrm{mg} / \mathrm{kg}$ body weight) for nine days, after which serum levels of cytokines, namely interleukin (IL)-2, -4, $-6,-10,-17 \mathrm{~A}$ and interferon (IFN)- $\alpha$ and $-\gamma$, were investigated by ELISA. CVG significantly promoted the secretion of IL-2, $-4,-6,-10,-17 \mathrm{~A}$ and IFN- $\alpha$ and $-\gamma$ at the doses of $100(\mathrm{P}<0.05)$ and $200(\mathrm{P}<0.01) \mathrm{mg} / \mathrm{kg}$, but not at $40 \mathrm{mg} / \mathrm{kg}(\mathrm{P}>0.05)$, when compared with cyclophosphamide treatment, as a positive control. Additionally, cytokine production associated with T helper (Th) 2 and Th17 cells was enhanced compared with that of Th1 cytokines, and the immunomodulatory function of CVG appeared to be IL-10-dependent. These results demonstrate that CVG may stimulate the production of cytokines and
\end{abstract}

Correspondence to: Professor Yi Xin, Department of Biotechnology, Dalian Medical University, 9 West Section, Lvshun South Road, Dalian, Liaoning 116044, P.R. China

E-mail: jimxin@hotmail.com

Professor Yufang Ma, Department of Biochemistry and Molecular Biology, Dalian Medical University, 9 West Section, Lvshun South Road, Dalian, Liaoning 116044, P.R. China

E-mail: yufang_ma@hotmail.com

Key words: Coriolus versicolor, glucan, cytokines, antitumor activity, sarcoma-180 serve as a Th2/IL-10-dependent immunomodulator, and thus has promise in supporting cancer therapies.

\section{Introduction}

The utilization of mushrooms for their medicinal properties is an established practice in Asian nations, though is less common in European regions (1). China is proposed to have 1,500-2,000 types of consumable mushrooms, of which 981 species have been verified (2). There has been previous interest in the use of mushrooms, not only as a healthy food sustenance containing fundamental components such as proteins and polysaccharides, but additionally as a source of bioactive secondary metabolites (phenolic compounds,terpenes, steroids) with beneficial properties, namely anti-inflammatory, antioxidant, immunomodulatory, anticarcinogenic, antiviral, antibacterial, antifungal, hepatoprotective, antineurodegenerative, antidiabetic, antiangiogenic, and hypoglycemic properties, among others (3). Mushrooms have been utilized as dietary supplements reciprocal to prescriptions for anticancer treatment. In addition, the reported antiviral, hypocholesterolemic and hepatoprotective properties of mushrooms (4) is concurrent with the identification of seven partially-purified polysaccharides with cancer preventative and immunomodulatory activities in consumable and therapeutic mushroom species (Agaricus biosporus, Agaricus brasiliensis, Phellinus linteus, Ganoderma lucidum, Ganoderma applanatum, Lentinus edodes and Trametes versicolor), all of which contained glucose as the prevalent monosaccharide, among varying amounts of other $\alpha$-glucans (3). Coriolus versicolor $(\mathrm{CV})$ is among the established species of edible mushrooms (5). The significance of CV has been acknowledged regarding it high content of biological compounds including polysaccharides (starch, chitin), phenols (gallic, protocatechuic acid, catechin), steroids (ergosterol), vitamins (B1, B2, C and D) and minerals (calcium, selenium) (3). Additionally, CV may have various pharmacological properties, including antitumor, 
immunomodulatory, cell reinforcement, antinociceptive, disease mitigative, antimicrobial, hepatoprotective and hypolipidemic effects (6).

Cancer therapy may involve several modalities, including surgery, radiotherapy, chemotherapy, immunotherapy, hormone therapy, bone marrow transplantation and alternative treatments, which may be used singly or in combination. The aim of cancer treatment is to contain and remove the primary tumor and to prevent its recurrence and/or metastasis (7). Therefore, to prevent health problems and to reduce the cost of medical treatment and healthcare, the development and use of effective natural drugs may aid to protect the body against certain side effects of chemotherapy and radiotherapy, and suppress the progression of many diseases (8). The development of novel drugs and health foods has thus become an important strategy in the biotechnology, food and medicinal industries (9). Improving and prolonging human life and resisting aging are important aims of both the general public and research $(10,11)$. These aims may be achievable through the development of novel drugs and health foods that promote human longevity and immunocompetence (12).

Glucans are considered to be the most well established and potent derivatives of mushrooms that have antitumor and immunomodulatory properties (13). Among the diverse glucans present in mushrooms are $\alpha$-glucans, which have also been identified in parasitic and bacterial cell communities (14). Notably, glucans have been indicated to increase the secretion of a range of key cytokines, including interleukins (ILs) and interferons (IFNs) $(15,16)$. Our group previously demonstrated the anticancer and immunomodulatory activities of a glucan from CV with potential as a therapeutic in cancer treatment (3). The present study aimed to determine the effect of a

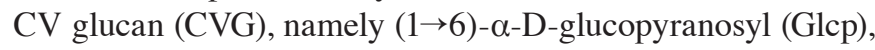
on the stimulation of cytokine production in a sarcoma-180 tumor-bearing mouse model.

\section{Materials and methods}

Materials. The fruiting body of CV used in the present study was from the Changbai Mountain region (Changchun, China) and was collected by Professor Yi Xin at the Department of Biotechnology, Dalian Medical University (Dalian, China). Specific pathogen free Kunming mice (18-20 g, 6-7-weeks-old, female, C57BL) were obtained from the Animal Center of Dalian Medical University. Other materials used included RPMI 1640 medium with improved nutrient solution (01-100-1A, 01-100-1B; Gibco; Thermo Fisher Scientific, Inc., Waltham, MA, USA), cyclophosphamide (Sigma-Aldrich; Merck KGaA, Darmstadt, Germany), sarcoma-180 cells (S-180; Nanjing KeyGen Biotech. Co. Ltd., Nanjing, China), and ELISA kits for IFN- $\alpha$ (411002; Thermo Fisher Scientific, Inc.) and $-\gamma($ KE00063) and IL-2 (KE00017), - 4 (KE00016), - 6 (KE00007), -10 (KE00012) and -17A (KE00015; ProteinTech Group, Inc., Rosemount, IL, USA). All reagents and chemicals used were of analytical grade.

The complete purification, characterization and biological activities of CVG have been reported in a previous study by our group (3).

The study was completed in strict accordance with the Guidelines for the Care and Use of Laboratory Animals of the National Institutes of Health (Bethesda, MA, USA), and was approved by the Committee for the Ethics of Animal Experiments of Dalian Medical University. After the treatment period, surgical procedures were performed following $250 \mathrm{mg} / \mathrm{kg}$ (intraperitoneal) sodium pentobarbital euthanasia (Abbott Pharmaceutical Co., Ltd., Lake Bluff, IL, USA) with efforts to minimize suffering.

Animals and treatment. A total of 60 mice were used in the present study, which were housed in conventional polycarbonate cages containing sawdust bedding under standard research facility conditions (room temperature, atmospheric oxygen, $12 \mathrm{~h}$ light-dark cycle and free access to standard mouse diet and water ad libitum). The mice were randomly divided into six groups $(\mathrm{n}=10)$, and $\mathrm{S}-180$ sarcoma cells $\left(0.2 \mathrm{ml}, 2 \times 10^{6}\right.$ cells) were injected subcutaneously into the right axilla of the mice in five groups, while the remaining served as a normal control. Thus, the groups were as follows: Normal control (treated with $0.2 \mathrm{ml}$ normal saline only); model control (inoculated with sarcoma-180 cells and treated with $0.2 \mathrm{ml}$ normal saline); positive control (inoculated with sarcoma-180 cells and treated with cyclophosphamide, $20 \mathrm{mg} / \mathrm{kg}$ body weight); and three groups injected with 40 , $100,200 \mathrm{mg} / \mathrm{kg}$ body weight CVG, respectively, following sarcoma-180 cells inoculation. The CVG was dissolved in normal saline, and intraperitoneally injected in a volume of $0.2 \mathrm{ml}$ daily for 9 days beginning $24 \mathrm{~h}$ after tumor cell transplantation. The formula of the CVG was $[\rightarrow 6)-\alpha-\mathrm{D}-$ Glcp- $(1 \rightarrow]_{n}$, as determined previously (3).

Measurement of IL-2, -4, -6, -10, -17A and IFN- $\alpha$ and $-\gamma$. The serum levels of IL-2, $-4,-6,-10,-17 \mathrm{~A}$ and IFN- $\alpha$ and $-\gamma$ were measured by ELISA as previously described (17). Briefly, following the treatment period, mice were euthanized and blood $(1.5 \mathrm{ml})$ was sampled from the eyeballs of the mice into a $2 \mathrm{ml}$ eppendorf tube and centrifuged for $15 \mathrm{~min}$ at $1,372 \mathrm{xg}$ at $4^{\circ} \mathrm{C}$. The upper fraction of clear serum was collected and the levels of IL-2, $-4,-6,-10,-17 \mathrm{~A}$ and IFN- $\alpha$ and $-\gamma$ in the serum were measured by ELISA according to kit instructions.

Statistical analysis. All experiments were conducted in triplicate, and data were presented as the mean \pm standard deviation. Statistical analysis was performed with GraphPad Prism version 5.0 (GraphPad Software, Inc., La Jolla, CA, USA). One-way analysis of variance followed by Fisher's least significant difference tests were used for statistical comparisons between the treatment and control groups, and $\mathrm{P}<0.05$ was considered to indicate a statistically significant difference.

\section{Results}

Effect of CVG on the stimulation of cytokine production. The effect of CVG on the production of IL-2, -4, -6, -10, -17A and IFN- $\alpha$ and $-\gamma$ were determined in sarcoma-180-bearing mice by ELISA (Figs. 1-7 and Tables I-VII, respectively). The administration of CVG resulted in significantly increased production of IL-2, $-4,-6,-10,-17 \mathrm{~A}$ and IFN- $\alpha$ and $-\gamma$ at doses of $100(\mathrm{P}<0.05)$ and $200(\mathrm{P}<0.01) \mathrm{mg} / \mathrm{kg}$ body weight when compared with the cyclophosphamide positive control group. 
Table I. Effect of CVG on IL-2 levels in the serum of sarcoma180-bearing mice.

\begin{tabular}{lcc}
\hline Groups & $\begin{array}{c}\text { Dose } \\
(\mathrm{mg} / \mathrm{kg})\end{array}$ & $\begin{array}{c}\text { IL-2 concentration } \\
(\mathrm{pg} / \mathrm{ml})\end{array}$ \\
\hline Normal & - & 4.77 \\
Model & - & 4.12 \\
Positive & 20 & 5.16 \\
CVG & 40 & 4.83 \\
CVG & 100 & $7.55^{\mathrm{a}}$ \\
CVG & 200 & $10.38^{\mathrm{b}}$ \\
\hline
\end{tabular}

Data are presented as the mean \pm standard deviation of three replicate experiments. ${ }^{\mathrm{a}} \mathrm{P}<0.05$ and ${ }^{\mathrm{b}} \mathrm{P}<0.01$ vs. positive (cyclophosphamide) group. CVG, Coriolus versicolor glucan $[(1 \rightarrow 6)-\alpha-\mathrm{D}-\mathrm{Glcp}]$; IL, interleukin

Table III. Effect of CVG on IL-6 levels in the serum of sarcoma-180-bearing mice.

\begin{tabular}{lcc}
\hline Group & Dose $(\mathrm{mg} / \mathrm{kg})$ & IL-6 concentration $(\mathrm{pg} / \mathrm{ml})$ \\
\hline Normal & - & 5.52 \\
Model & - & 5.21 \\
Positive & 20 & 7.12 \\
CVG & 40 & 6.49 \\
CVG & 100 & $7.54^{\mathrm{a}}$ \\
CVG & 200 & $21.93^{\mathrm{b}}$ \\
\hline
\end{tabular}

Data are presented as the mean \pm standard deviation of three replicate experiments. ${ }^{\mathrm{a}} \mathrm{P}<0.05$ and ${ }^{\mathrm{b}} \mathrm{P}<0.01$ vs. positive (cyclophosphamide) group. CVG, Coriolus versicolor glucan $[(1 \rightarrow 6)-\alpha-\mathrm{D}-\mathrm{Glcp}]$; IL, interleukin.

Table V. Effect of CVG on IL-17A levels in the serum of sarcoma-180-bearing mice.

\begin{tabular}{lcc}
\hline Group & Dose $(\mathrm{mg} / \mathrm{kg})$ & $\mathrm{IL}-10$ concentration $(\mathrm{pg} / \mathrm{ml})$ \\
\hline Normal & - & 12.41 \\
Model & - & 7.94 \\
Positive & 20 & 9.06 \\
CVG & 40 & 8.26 \\
CVG & 100 & $11.88^{\mathrm{a}}$ \\
CVG & 200 & $20.68^{\mathrm{b}}$ \\
\hline
\end{tabular}

Data are presented as the mean \pm standard deviation of three replicate experiments. ${ }^{\mathrm{a}} \mathrm{P}<0.05$ and ${ }^{\mathrm{b}} \mathrm{P}<0.01$ vs. positive (cyclophosphamide)

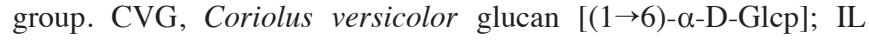
interleukin.

Meanwhile, following stimulation with $40 \mathrm{mg} / \mathrm{kg} \mathrm{CVG}$, the levels of the different cytokines did not differ significantly compared with the positive control group. Following CVG
Table II. Effect of CVG on IL-4 levels in the serum of sarcoma180-bearing mice.

\begin{tabular}{lcc}
\hline Groups & $\begin{array}{c}\text { Dose } \\
(\mathrm{mg} / \mathrm{kg})\end{array}$ & $\begin{array}{c}\text { IL-4 concentration } \\
(\mathrm{pg} / \mathrm{ml})\end{array}$ \\
\hline Normal & - & 3.95 \\
Model & - & 3.47 \\
Positive & 20 & 6.66 \\
CVG & 40 & 6.12 \\
CVG & 100 & $10.62^{\mathrm{a}}$ \\
CVG & 200 & $16.78^{\mathrm{b}}$ \\
\hline
\end{tabular}

Data are presented as the mean \pm standard deviation of three replicate experiments. ${ }^{\mathrm{a}} \mathrm{P}<0.05$ and ${ }^{\mathrm{b}} \mathrm{P}<0.01$ vs. positive (cyclophosphamide) group. CVG, Coriolus versicolor glucan [(1 $\rightarrow 6)-\alpha-\mathrm{D}-\mathrm{Glcp}]$; IL, interleukin.

Table IV. Effect of CVG on IL-10 levels in the serum of sarcoma-180-bearing mice.

\begin{tabular}{lcc}
\hline Group & Dose $(\mathrm{mg} / \mathrm{kg})$ & IL-10 concentration $(\mathrm{pg} / \mathrm{ml})$ \\
\hline Normal & - & 4.87 \\
Model & - & 3.80 \\
Positive & 20 & 15.73 \\
CVG & 40 & 14.55 \\
CVG & 100 & $17.20^{\mathrm{a}}$ \\
CVG & 200 & $89.79^{\mathrm{b}}$ \\
\hline
\end{tabular}

Data are presented as the mean \pm standard deviation of three replicate experiments. ${ }^{\mathrm{a}} \mathrm{P}<0.05$ and ${ }^{\mathrm{b}} \mathrm{P}<0.01$ vs. positive (cyclophosphamide) group. CVG, Coriolus versicolor glucan [( $1 \rightarrow 6)-\alpha-\mathrm{D}-\mathrm{Glcp}]$; IL, interleukin.

Table VI. Effect of CVG on IFN- $\alpha$ levels in the serum of sarcoma-180-bearing mice.

\begin{tabular}{lcc}
\hline Group & Dose $(\mathrm{mg} / \mathrm{kg})$ & IFN- $\alpha$ concentration $(\mathrm{pg} / \mathrm{ml})$ \\
\hline Normal & - & 7.41 \\
Model & - & 6.53 \\
Positive & 20 & 8.94 \\
CVG & 40 & 8.30 \\
CVG & 100 & $12.41^{\mathrm{a}}$ \\
CVG & 200 & $33.98^{\mathrm{b}}$
\end{tabular}

Data are presented as the mean \pm standard deviation of three replicate experiments. ${ }^{\mathrm{a}} \mathrm{P}<0.05$ and ${ }^{\mathrm{b}} \mathrm{P}<0.01$ vs. positive (cyclophosphamide) group. CVG, Coriolus versicolor glucan [(1-6)- $\alpha-\mathrm{D}-\mathrm{Glcp}]$; IFN, interferon.

stimulation, the Th2-associated cytokines (IL-4, -6 and principally-10) $(18,19)$ and Th17 cytokine (IL-17A) (19) were produced at notably higher levels compared with the 
Table VII. Effect of CVG on IFN- $\gamma$ levels in the serum of sarcoma-180-bearing mice.

\begin{tabular}{lcc}
\hline Group & Dose $(\mathrm{mg} / \mathrm{kg})$ & IFN- $\gamma$ concentration $(\mathrm{pg} / \mathrm{ml})$ \\
\hline Normal & - & 6.95 \\
Model & - & 5.46 \\
Positive & 20 & 7.59 \\
CVG & 40 & 7.32 \\
CVG & 100 & $7.92^{\mathrm{a}}$ \\
CVG & 200 & $11.41^{\mathrm{b}}$ \\
\hline
\end{tabular}

Data are presented as the mean \pm standard deviation of three replicate experiments. ${ }^{\mathrm{a}} \mathrm{P}<0.05$ and ${ }^{\mathrm{b}} \mathrm{P}<0.01$ vs. positive (cyclophosphamide) group. CVG, Coriolus versicolor glucan [(1-6)- $\alpha$-D-Glcp]; IFN, interferon.

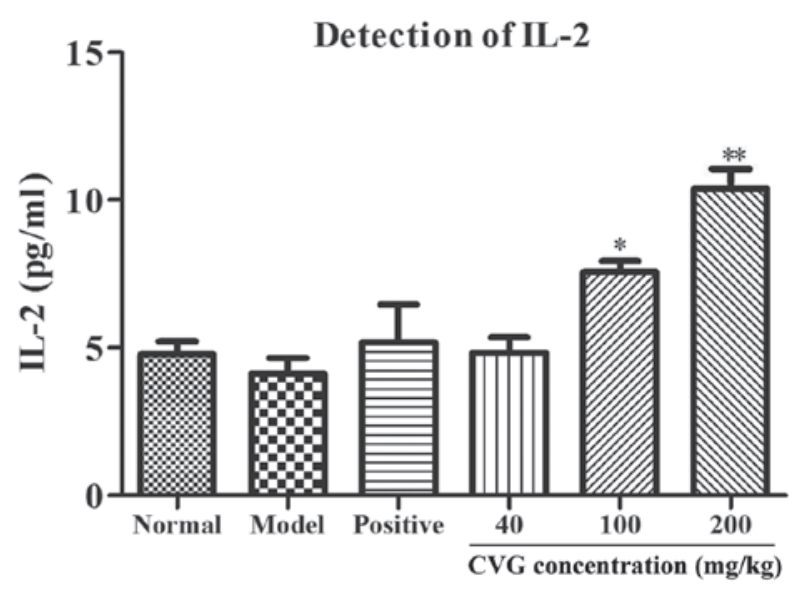

Figure 1. Effect of CVG on serum IL-2 levels in sarcoma-180-bearing mice. ${ }^{*} \mathrm{P}<0.05$ and ${ }^{* *} \mathrm{P}<0.01$ vs. positive group. $\mathrm{CVG}$, Coriolus versicolor glucan $[(1 \rightarrow 6)-\alpha-\mathrm{D}-\mathrm{Glcp}]$; IL, interleukin.

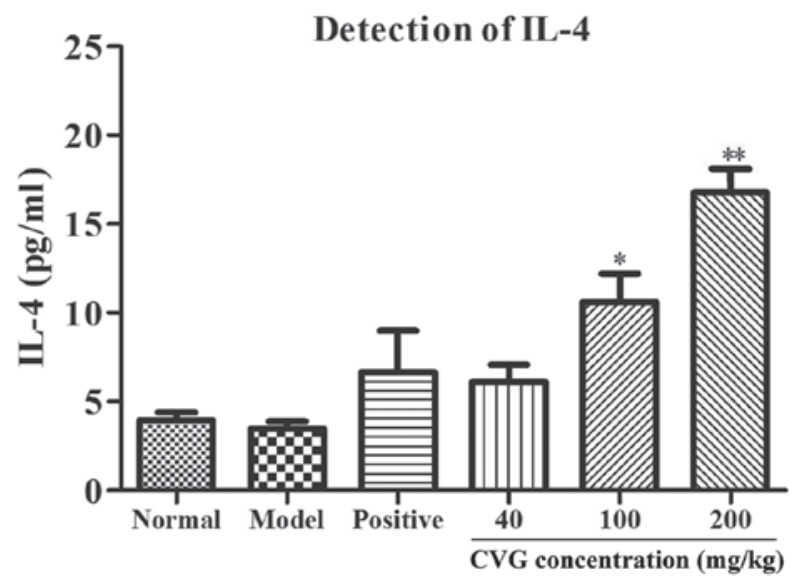

Figure 2. Effect of CVG on serum IL-4 levels in sarcoma-180-bearing mice. ${ }^{*} \mathrm{P}<0.05$ and ${ }^{* *} \mathrm{P}<0.01$ vs. positive group. CVG, Coriolus versicolor glucan $[(1 \rightarrow 6)-\alpha-D-G l c p] ;$ IL, interleukin.

Th1-associated cytokines (IL-2 and IFN- $\gamma$ ) (14). These results indicate that CVG may promote the secretion of cytokines from $\mathrm{T}$ cells, particularly of cytokines associated

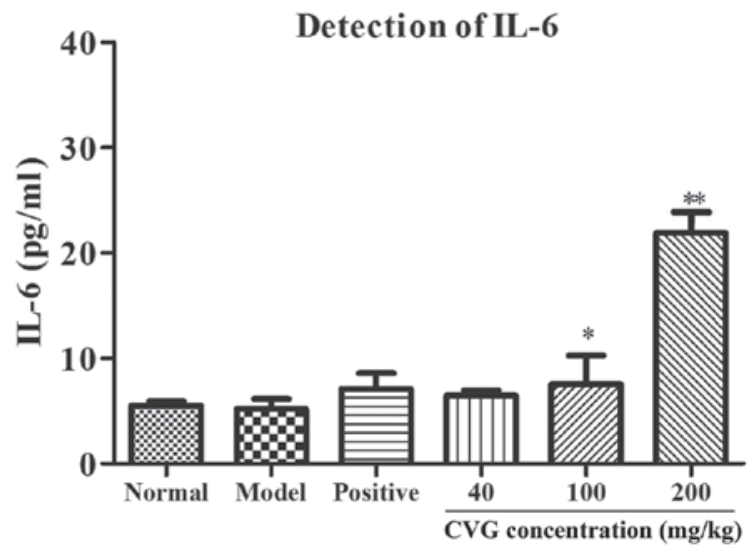

Figure 3. Effect of CVG on serum IL-6 levels in sarcoma-180-bearing mice. ${ }^{*} \mathrm{P}<0.05$ and ${ }^{* *} \mathrm{P}<0.01$ vs. positive group. CVG, Coriolus versicolor glucan $[(1 \rightarrow 6)-\alpha-\mathrm{D}-\mathrm{Glcp}]$; IL, interleukin.

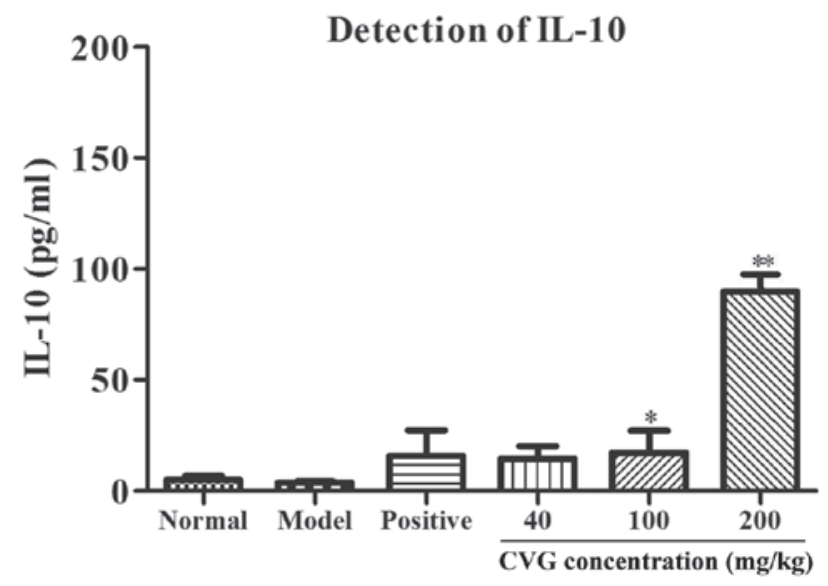

Figure 4. Effect of CVG on serum IL-10 levels in sarcoma-180-bearing mice. ${ }^{*} \mathrm{P}<0.05$ and ${ }^{* *} \mathrm{P}<0.01$ vs. positive group. CVG, Coriolus versicolor glucan $[(1 \rightarrow 6)-\alpha-\mathrm{D}-\mathrm{Glcp}] ;$ IL, interleukin.

with Th2-mediated humoral immunity and Th2 proliferation and differentiation such as IL-4 and -6 (14). Thus, CVG may enhance Th2-mediated humoral immunity, as an established prerequisite for improved adaptive immunity (18).

\section{Discussion}

The present study aimed to identify the impact of the glucan $(1 \rightarrow 6)-\alpha-D-G l c p$ purified from $\mathrm{CV}$ on the stimulation of cytokine production in a mouse model of sarcoma-180. CV is considered as an important medicinal agent due to its provision of essential nutrients and therapeutic applications, particularly regarding its apparent pharmacological properties of antitumor, immunomodulatory, cell reinforcement, antinociceptive, disease mitigative, antimicrobial, hepatoprotective and hypolipidemic activities, among others (5). A control cyclophosphamide group was used in the present study, as cyclophosphamide is frequently used as a chemotherapeutic for the treatment of cancer, due to its targeting of rapidly dividing cells (despite some interference with normal cell development) (20). Therefore, this enabled a comparison between CVG and an official drug used for cancer treatment. 


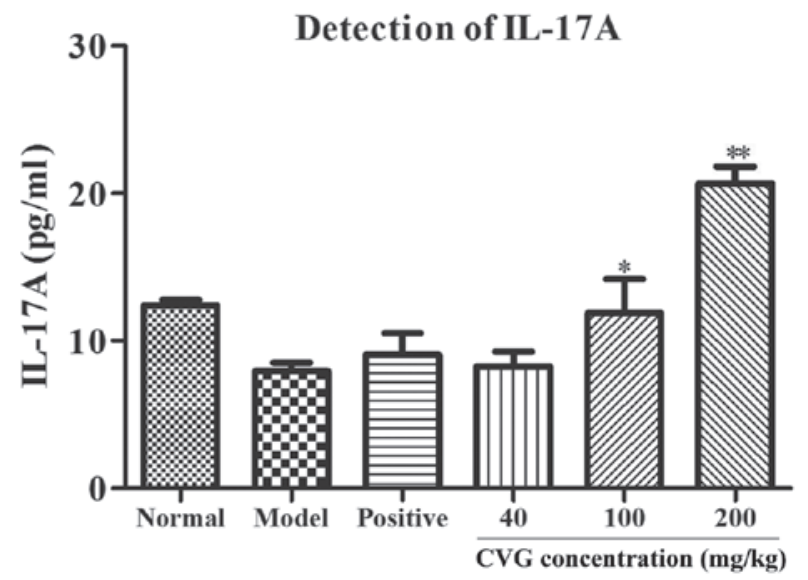

Figure 5. Effect of CVG on serum IL-17A levels in sarcoma-180-bearing mice. ${ }^{*} \mathrm{P}<0.05$ and ${ }^{* *} \mathrm{P}<0.01$ vs. positive group. $\mathrm{CVG}$, Coriolus versicolor glucan $[(1 \rightarrow 6)-\alpha-\mathrm{D}-\mathrm{Glcp}]$; IL, interleukin.

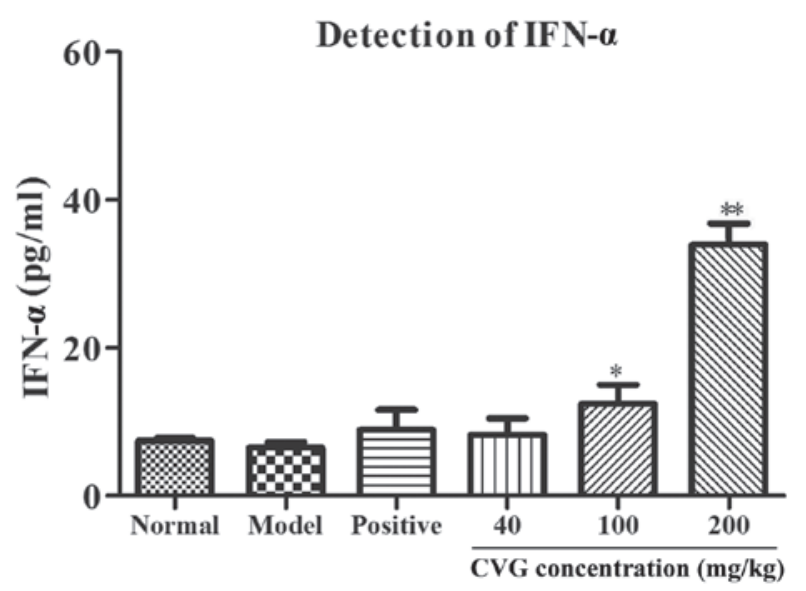

Figure 6. Effect of CVG on serum IFN- $\alpha$ levels in sarcoma-180-bearing mice. ${ }^{*} \mathrm{P}<0.05$ and ${ }^{* *} \mathrm{P}<0.01$ vs. positive group. $\mathrm{CVG}$, Coriolus versicolor glucan $[(1 \rightarrow 6)-\alpha-\mathrm{D}-\mathrm{Glcp}]$; IFN, interferon.

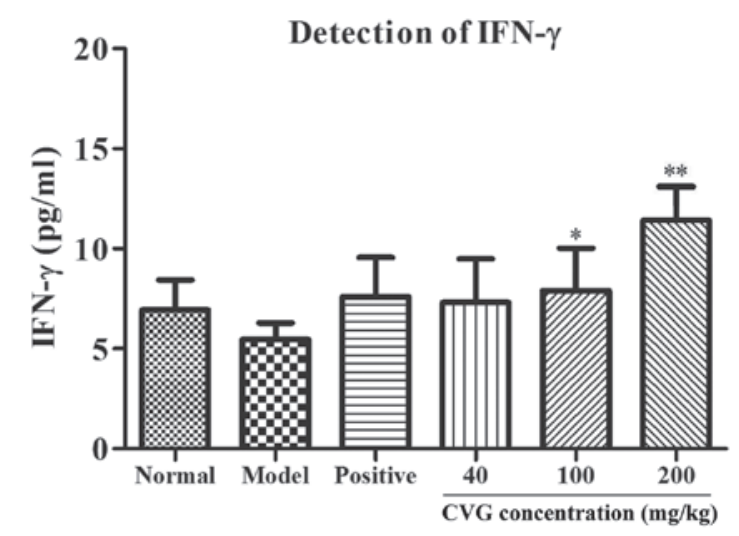

Figure 7. Effect of CVG on serum IFN- $\gamma$ levels in sarcoma-180-bearing mice. ${ }^{*} \mathrm{P}<0.05$ and ${ }^{* *} \mathrm{P}<0.01$ vs. positive group. $\mathrm{CVG}$, Coriolus versicolor glucan $[(1 \rightarrow 6)-\alpha-D-G l c p] ;$ IFN, interferon.

Cytokines are cell signaling molecules that are expressed in peptide, protein and glycoprotein forms (21). ILs and IFNs are two specialist types of cytokine required in the management of immune system responses to disease and viral invasion (22). In the present study, serum cytokine production was investigated using ELISA. Specifically, the cytokines IL-2, -4, -6, -10, -17A and IFN- $\alpha$, and $-\gamma$; associated with Th1 (IFN- $\gamma$ and IL-2), Th2 (IL-10, -4 and -6 and IFN- $\alpha$ ) and Th17 (IL-17A) cells, were investigated to elucidate the fundamental systems by which CVG may exert anticancer effects in a tumor-bearing mouse model.

IL-2 is a T cell-differentiating cytokine and improves the cytolytic activities of cytotoxic $\mathrm{T}$ lymphocytes and natural killer (NK) cells (23). Meanwhile, IL-4 serves a key role by stimulating the differentiation of naive $\mathrm{T}$ cells ( $\mathrm{Th} 0$ cells) to Th2 cells (24). IL-6 is secreted by T cells and macrophages to enhance the immune reaction (25), to aid the differentiation and proliferation of $\mathrm{T}$ and $\mathrm{B}$ cells, and to advance the development of plasma cells from B cells (26). IL-10, also known as a human cytokine synthesis inhibitory factor, is an inhibitory cytokine that may hinder pathogen invasion and improve immunopathology (27). Conversely, IL-17A is involved in initiating and mediating proinflammatory reactions generally associated with unfavorably susceptible responses (28). IFN- $\alpha$ may activate resistant cells including cytotoxic $\mathrm{T}$ cells and macrophages (29). IFN- $\gamma$ is a primary member of the class II IFNs that may specifically prevent viral replication and exert immunostimulatory and immunomodulatory impacts (20).

CVG significantly stimultated 1, 2 and Th17 cytokine production at the doses of 100 and $200 \mathrm{mg} / \mathrm{kg}$, but not at $40 \mathrm{mg} / \mathrm{kg}$, compared with the control cyclophosphamide group. Additionally, 2- and Th17-dependent cytokines were observed at higher levels compared with Th1 cytokines; most notably, IL-10 concentration markedly exceeded that of the other cytokines.

Th1 and 2 cytokines serve essential roles in immune regulation, including in antitumor resistance (30). Despite results suggesting that $\mathrm{Th} 1$ is dominant over Th2 immunity in the induction of antitumor responses (30), the current data suggested that CVG served as a Th2 immune-inducer through IL-10-dependent pathways. Similarly, gene therapy utilizing Th 2 cytokines, including IL-4, -6 and -10 , has been reported to be effective in tumor immunotherapy $(19,30,31)$. Thus, despite increased levels of IL-10 in numerous cancers and its association with poor prognosis (30), CVG may exert its apparent anticancer effects through the beneficial immunomodulatory functions of IL-10, among other mechanistic pathways. The beneficial effect of IL-10, as a potent anti-inflammatory cytokine produced by monocytes, mast cells, macrophages and dendritic cells, has been reported in a number of cancers, including melanoma and breast and ovarian cancers, and may occur through its suppression of major histocompatibility complex-I activity and induction of NK-mediated tumor lysis $(14,18,19)$. Furthermore, IL-10 has been identified to suppress the growth and metastasis of tumors by inhibiting the production of angiogenic factors $(19,31)$.

Inflammation is a hallmark of cancer and the suppression of inflammatory pathways has been targeted in cancer therapy $(32,33)$. IL-10 inhibits nuclear factor- $\kappa \mathrm{B}$ signaling, a key inflammatory pathway, and thus downregulates proinflammatory cytokine expression in its role as an antitumor cytokine (14). Furthermore, in previous studies, IL-10 therapy inhibited colon inflammation and carcinoma, 
while its deficiency in an experimental murine animal model resulted in bacteria-induced carcinogenesis $(30,31)$.

The antitumor effect of CVG may partly occur through the cellular immune response, particularly through spleen lymphocyte proliferation, and CVG may serve as an immunomodulator; thus indicating its potential to regulate the immune system to control infections and other adverse health effects, with these suppressive and/or potentiating functions likely benefiting overall health (3). IL-10 drives the immune system to aid B cells secrete protective antibodies, and in effect suppresses the secretion of IL- 2 and IFN- $\gamma$ from Th1 cells $(30,31)$, as reflected in the present study, and thus may account for the antitumor activity of CVG. Our group previously reported that incubation of tumor cells with glucans suppressed the growth of the tumors both in vitro and in vivo, by arresting the cell cycle and promoting apoptosis (3). However, only $0.2 \mathrm{ml} \mathrm{CVG}$ was injected into the mice per day for nine days (3) and thus for CV-derived glucans to be applied in the medicinal and food industries, more detailed studies are required. Nevertheless, the present article provides insight into the activity of $\mathrm{CVG}$, and may provide a basis for future interpretation of the bioactivities of $\mathrm{CV}$ extracts. Additionally, the present study may aid in the selection of appropriate $\alpha$-glucans for future clinical investigations.

In conclusion, the glucan $(1 \rightarrow 6)-\alpha-D-G l c p$ isolated from $\mathrm{CV}$ stimulated the production of cytokines, and its potential immunomodulatory and anticancer effects were implicated to be IL-10/Th2-dependent. These results indicate the potential of CVG to enhance human health as a natural supplement when used in the food industry and in cancer therapies.

\section{Acknowledgements}

The present work was supported by the Science and Technology Department Program of Liaoning Province, China (grant no. $2,011,225,013)$.

\section{References}

1. Dai X, Stanilka JM, Rowe CA, Esteves EA, Nieves C Jr, Spaiser SJ, Christman MC, Langkamp-Henken B and Percival SS: Consuming Lentinula edodes (Shiitake) mushrooms daily improves human immunity: A randomized dietary intervention in healthy young adults. J Am Coll Nutr 34: 478-487, 2015.

2. Esposito P, La Porta E, Calatroni M, Bianzina S, Libetta C, Gregorini M, Rampino T and Dal Canton A: Renal involvement in mushroom poisoning: The case of Orellanus syndrome. Hemodial Int 19: E1-E5, 2015.

3. Awadasseid A HJ, Gamallat Y, Xueqi S, Eugene KD, Musa Hago A, et al: Purification, characterization, and antitumor activity of a novel glucan from the fruiting bodies of Coriolus Versicolor. PloS one 12: e0171270, 2017.

4. Dimitrijevic MV, Mitic VD, Cvetkovic JS, Stankov VPJ, Mutic JJ, Snezana D and Mandic N: Update on element content profiles in eleven wild edible mushrooms from family Boletaceae. Eur Food Res Technol 242: 1-10, 2016.

5. Ekwemalor K, Asiamah E and Worku M: Effect of a mushroom (Coriolus versicolor) based probiotic on the expression of toll-like receptors and signal transduction in goat neutrophils. J Mol Biol Res 6: 71-79, 2016.

6. Wahyuningsih SPA, Pramudya M and Sugiharto S: Influence of polysaccharide krestin from Coriolus versicolor extract on nitrite and malondialdehyde concencentrations of Mus musculus serum exposed by Mycobacterium tuberculosis. Biosaintifika 8: 12-17, 2016.

7. Qin SY, Zhang AQ, Cheng SX, Rong L and Zhang XZ: Drug self-delivery systems for cancer therapy. Biomaterials 112: 234-247, 2017.
8. Wang H, Yu J, Lu X and He X: Nanoparticle systems reduce systemic toxicity in cancer treatment. Nanomedicine (Lond) 11: 103-106, 2016.

9. Wu YL, Zhou L and Lu Y: Intrathecal chemotherapy as a treatment for leptomeningeal metastasis of non-small cell lung cancer: A pooled analysis. Oncol Lett 12: 1301-1314, 2016.

10. Gong Y, Yang C, Yin X, Zhu M, Yang H, Wang Y, Li Y, Liu L, Dong X, Cao S, et al: The effect of essential medicines programme on rational use of medicines in China. Health Policy Plan 31: 21-27, 2016

11. Wang N, Awadasseid A, Yuan Y, Cui J, Guo T, Gou D, Bai Y, Zhou Y, and Gao J: Biotransformation of ginsenoside Rb1 for ginsenoside $\mathrm{Rd}$ preparation by Lysinibacillus massiliensis No 24. Indian J Biotechnol 15: 400-406, 2016.

12. Elbe S, Roemer-Mahler A and Long C: Medical countermeasures for national security: A new government role in the pharmaceuticalization of society. Soc Sci Med 131: 263-271, 2015.

13. Prasad S, Rathore H, Sharma S and Yadav AS: Medicinal mushrooms as a source of novel functional food. Int J Food Sci Nutr Diet 4: 221-225, 2015.

14. Khan MS, Zhang X, You L, Fu X, and Abbasi AM: Structure and bioactivities of fungal polysaccharides. Polysaccharides: Bioactivity and Biotechnology: 1-14, 2014.

15. Habijanic J, Berovic M, Boh B, Plankl M and Wraber B: Submerged cultivation of Ganoderma lucidum and the effects of its polysaccharides on the production of human cytokines TNF- $\alpha$, IL-12, IFN- $\gamma$, IL-2, IL-4, IL-10 and IL-17. N Biotechnol 32: 85-95, 2015.

16. Ali MF, Driscoll CB, Walters PR, Limper AH and Carmona EM: $\beta$-glucan-activated human B lymphocytes participate in innate immune responses by releasing proinflammatory cytokines and stimulating neutrophil chemotaxis. J Immunol 195: 5318-5326, 2015

17. Wagener AH, de Nijs SB, Lutter R, Sousa AR, Weersink EJ, Bel EH and Sterk PJ: External validation of blood eosinophils, $\mathrm{FE}(\mathrm{NO})$ and serum periostin as surrogates for sputum eosinophils in asthma. Thorax 70: 115-120, 2015.

18. Szymczak I and Pawliczak R: The active metabolite of vitamin D3 as a potential immunomodulator. Scand J Immunol 83: 83-91, 2016.

19. Landskron G, De la Fuente M, Thuwajit P, Thuwajit C and Hermoso MA: Chronic inflammation and cytokines in the tumor microenvironment. J Immunol Res 2014: 1-19, 2014.

20. Parker BS, Rautela J and Hertzog PJ: Antitumour actions of interferons: Implications for cancer therapy. Nat Rev Cancer 16: $131-144,2016$.

21. Khodabandehloo H, Gorgani-Firuzjaee S, Panahi G and Meshkani R: Molecular and cellular mechanisms linking inflammation to insulin resistance and $\beta$-cell dysfunction. Transl Res 167: 228-256, 2016.

22. Tavakolpour S and Tavakolpour V: Interleukin 4 inhibition as a potential therapeutic in pemphigus. Cytokine 77: 189-195, 2016.

23. Martin NT and Martin MU: Interleukin 33 is a guardian of barriers and a local alarmin. Nat Immunol 17: 122-131, 2016.

24. Conti P and Kempuraj D: Important role of mast cells in multiple sclerosis. Mult Scler Relat Disord 5: 77-80, 2016.

25. Schmidt-Arras D and Rose-John S: IL-6 pathway in the liver: From physiopathology to therapy. J Hepatol 64: 1403-1415, 2016.

26. Raggi C, Mousa HS, Correnti M, Sica A and Invernizzi P: Cancer stem cells and tumor-associated macrophages: A roadmap for multitargeting strategies. Oncogene 35: 671-682, 2016.

27. Chang WS, Liao CH, Tsai CW, Hu PS, Wu HC, Hsu SW, Ji HX, Hsiao CL and Bau DT: The role of IL-10 promoter polymorphisms in renal cell carcinoma. Anticancer Res 36: 2205-2209, 2016.

28. Cai S, Batra S, Langohr I, Iwakura Y and Jeyaseelan S: IFN- $\gamma$ induction by neutrophil-derived IL-17A homodimer augments pulmonary antibacterial defense. Mucosal Immunol 9: 718-729, 2016.

29. Miyazaki Y and Niino M: Endogenous type I interferons and their regulators in multiple sclerosis. Clin Exp Neuroimmunol 8: 17-23, 2017

30. Lippitz BE: Cytokine patterns in patients with cancer: A systematic review. Lancet Oncol 14: e218-e228, 2013.

31. Mannino MH, Zhu Z, Xiao H, Bai Q, Wakefield MR and Fang Y: The paradoxical role of IL-10 in immunity and cancer. Cancer Lett 367: 103-107, 2015.

32. Snaric J: Link between colorectal cancer and bacteria by Tom Noerper: 2014

33. Balkwill $\mathrm{F}$ and Mantovani A: Inflammation and cancer: Back to Virchow? Lancet 357: 539-545, 2001. 